\title{
Índice de dispersão de agregados de um Latossolo Vermelho distroférrico cultivado com cana sob aplicação de vinhaça
}

\section{Dispersion index of aggregates in a Rhodic Ferrasol cultivated with cane under stillage application}

\author{
Eber Augusto Ferreira do Prado ${ }^{1 *}$; Antonio Carlos Tadeu Vitorino'; \\ Wellinton Henrique de Oliveira ${ }^{3}$; Daniel Luan Pereira Espindola ${ }^{3}$; \\ Heverton Ponce Arantes ${ }^{4}$
}

\begin{abstract}
Resumo
As usinas de álcool e açúcar geram resíduos, sendo um deles a vinhaça a qual necessita de destino adequado. Uma das alternativas é a aplicação deste resíduo para melhoria de atributos do solo. Objetivouse com esse trabalho avaliar o efeito da vinhaça na agregação do solo, em três épocas de coleta e a produtividade da cana-de-açúcar cultivada. O estudo foi realizado em área cultivada com cana soca de terceiro ano em um Latossolo Vermelho distroférrico, de textura franco argilo arenoso no município de Ponta Porã, MS. O delineamento experimental foi de blocos casualizados, com cinco repetições, em parcelas sub-subdivididas, sendo quatro doses de vinhaça $\left(0 ; 450 ; 600\right.$ e $\left.750 \mathrm{~m}^{3} \mathrm{ha}^{-1}\right)$, quatro camadas $(0,0-0,05 ; 0,05-0,10 ; 0,10-0,20$ e $0,20-0,40 \mathrm{~m})$, e três épocas de coleta, aos 38 , 75 e 111 dias após aplicação das doses de vinhaça, em parcelas de $24 \mathrm{~m}^{2}(6 \mathrm{~m} \times 4 \mathrm{~m})$. Para a determinação do índice de dispersão dos agregados (ID) foram obtidas amostras de solo com estrutura preservada aos 38,75 e 111 dias após aplicação das doses de vinhaça. Nas maiores doses de vinhaça o teor de potássio, de matéria orgânica e a estabilidade dos agregados aumentou e o índice de dispersão dos agregados diminuiu.
\end{abstract}

Palavras-chave: Ultrassom, cana-de-açúcar, estabilidade de agregados

\begin{abstract}
The sugar and alcohol plants generate waste stillage one that needs proper destination. One alternative is the application of this residue to improve soil properties. The objective of this study was to evaluate the effect of stillage in the aggregation and productivity of sugar cane grown in three seasons of the soil sampling. The study was conducted in an Red dystrophic Latosol, sandy clay frank, at the BUNGE Monte Verde plant in the municipality of Ponta Porã, MS, Brasil. Cultivated with sugarcane third year. We used the $(4 \times 4)$ factorial design, evaluated 4 applications of stillage $\left(0,450,600\right.$ and $\left.750 \mathrm{~m}^{3} \mathrm{ha}^{-1}\right)$ and their soil characteristics measured at four depths $(0,0-0,5 ; 0,5-0,10 ; 0,10-0,20 ; 0,20-0,40 \mathrm{~m})$ with five repetitions. To determine the rate of dispersion of aggregates (ID) sample were obtained undisturbed soil at 38,75 and 111 days after application of stillage. With increasing doses of stillage were increased concentrations of potassium and organic matter and reduce the rate of dispersion and increased stability of soil aggregates.

Key words: Ultrasound, sugar cane, aggregate stability
\end{abstract}

\footnotetext{
${ }^{1}$ Discente de Doutorado em Agronomia, Programa de Pós-Graduação em Agronomia; Universidade Federal da Grande Dourados, UFGD, Dourados, MS. E-mail: eberprado@hotmail.com

${ }^{2}$ Prof. Dr. Adjunto, Faculdade de Ciências Agrárias, UFGD, Dourados, MS. E-mail: antoniovitorino@ufgd.edu.br

${ }^{3}$ Discentes de Graduação em Agronomia, UFGD, Dourados, MS. E-mail: welitonholiveira@hotmail.com; danielluanblz@hotmail.com

${ }^{4}$ Discente de Mestrado em Agronomia, Programa de Pós-Graduação em Agronomia, UFGD, Dourados, MS. E-mail: hevertonarantes@hotmail.com

* Autor para correspondência
} 


\section{Introdução}

As atuais técnicas de manejo da cultura da canade-açúcar utilizam intenso revolvimento do solo por ocasião do plantio, com o uso de arados, grades pesadas e subsoladores. O cultivo intensivo do solo e seu preparo em condições inadequadas alteram os fatores de crescimento das culturas (CENTURION et al., 2007). Além disso, a área sob colheita mecanizada aumenta grandemente e pode trazer problemas de alteração das condições estruturais dos solos cultivados. Portanto, a compreensão e a quantificação do impacto do uso e manejo do solo na sua qualidade física são fundamentais no desenvolvimento de sistemas agrícolas sustentáveis (DEXTER; YOUNGS, 1992). Nestas áreas sob uso intensivo é comum a utilização da fertirrigação com a vinhaça, especialmente como fonte de potássio para cana-de-açúcar, sendo sua aplicação um destino adequado a esse co-produto da fabricação do álcool (CAMILOTTI et al., 2006).

Também por ser rica em potássio e matéria orgânica e em outros nutrientes a vinhaça pode alterar a estrutura dos solos (LAVANHOLI, 2010). Neste sentido a aplicação de vinhaça por longos anos, ou sua aplicação em elevadas doses pode modificar a dispersão e floculação da argila no solo. Segundo Vicente et al. (2012) amostras de solo coletadas em áreas com aplicação de vinhaça, nas camadas de 0-0,20 e 0,20-0,40 m, apresentaram maiores valores de DMP e de agregados estáveis em água $>2,00 \mathrm{~mm}$. Silva et al. (2006) citam que a aplicação de vinhaça promove mudanças nos atributos químicos do solo, podendo também alterar seus atributos físicos, principalmente a estabilidade de agregados e a dispersão de argila do solo.

A elevada concentração de cátions dentre eles principalmente o potássio proveniente das aplicações sucessivas ou elevadas doses de vinhaça modifica a espessura da dupla camada difusa. Esta espessura é afetada, pela concentração e pelo tipo de eletrólito presente no meio de dispersão. Cátions com alto grau de hidratação são considerados dispersantes, aumentando a distância entre as partículas. Já cátions com baixo grau de hidratação minimizam as forças de repulsão e são considerados floculantes (MEURER, 2010).

Após a aproximação das partículas minerais, os óxidos de Fe e de Al e a matéria orgânica são agentes determinantes da estabilização dos agregados (VITORINO et al., 2003; PASSARIN et al., 2007; SANTOS, 2008; MEURER, 2010). Neste sentido, a vinhaça tem potencial de alterar os atributos físicos do solo por conter grande quantidade de matéria orgânica e elevada concentração de potássio. As aplicações sucessivas por longos períodos pode também aumentar o teor de matéria orgânica e com isso, melhorar a condição física do solo (CANELLAS et al., 2003). Com o incremento do teor de matéria orgânica ocorre aumento da quantidade de agregados estáveis em água o que melhora a distribuição de micro e macroporos do solo, favorecendo sua aeração e capacidade de infiltração, retenção de água. (VICENTE et al., 2012, PASSARIM et al., 2007). A análise de determinados atributos físicos do solo, como estabilidade de agregados via úmida e, mais recentemente, o índice de dispersão com uso do aparelho de ultrassom podem auxiliar a determinar a qualidade física do solo, que segundo van Lier (2010) é um atributo intrínseco deste, a qual pode ser inferida a partir de suas características e propriedades ou observações indiretas. Com isso, pode-se estabelecer uma relação entre o índice de dispersão e a estabilidade dos agregados do solo, como em estudos realizados por Sá, Lima e Mello (2002) e Ribeiro (2009), que utilizaram esse indicador no estudo da qualidade física do solo

Objetivou-se com esse trabalho avaliar o efeito de doses de vinhaça sobre a estabilidade de agregados e a produtividade da cana-de-açúcar cultivada em Latossolo Vermelho distroférrico, em três épocas de coleta. 


\section{Material e Métodos}

O trabalho foi realizado a campo na área comercial da Usina Monte Verde (BUNGE - SA), no município de Ponta Porã / MS, entre dezembro de 2010 e agosto de 2011. O local situa-se em latitude de $22^{\circ} 16^{\prime} 53^{\prime \prime} \mathrm{S}$ e longitude $55^{\circ} 07^{\prime}$ 56 ”'W, com altitude de $400 \mathrm{~m}$. O clima da região de acordo com a classificação de Köppen é do tipo
Cwa (mesotérmico úmido), com verão chuvoso e inverno seco. Durante a condução do experimento a precipitação pluviométrica total foi de $1.059 \mathrm{~mm}$.

O solo da área experimental foi classificado como Latossolo Vermelho distroférrico, textura média, com $540 \mathrm{~g} \mathrm{~kg}^{-1}$ areia, $360 \mathrm{~g} \mathrm{~kg}^{-1}$ de argila e $100 \mathrm{~g} \mathrm{~kg}^{-1}$ de silte. As características químicas na camada de 0 - $20 \mathrm{~cm}$ foram (Tabela 1 ).

Tabela 1. Análise química do solo da área experimental.

\begin{tabular}{ccccccccccc}
\hline $\begin{array}{c}\text { Camada } \\
\mathrm{m}\end{array}$ & $\begin{array}{c}\mathrm{pH} \\
\mathrm{Cacl}_{2}\end{array}$ & $\begin{array}{c}\mathrm{M.O} \\
\mathrm{g} \mathrm{Kg}^{-1}\end{array}$ & $\begin{array}{c}\mathrm{P} \\
\mathrm{mg} \mathrm{dm}^{-1}\end{array}$ & $\mathrm{H}+\mathrm{Al}$ & $\mathrm{K}$ & $\begin{array}{c}\mathrm{Ca} \\
\mathrm{Cmol}_{c}\end{array}$ & $\begin{array}{c}\mathrm{Mg} \\
\mathrm{dm}^{-3}\end{array}$ & $\mathrm{CTC}$ & $\mathrm{SB}$ & $\begin{array}{c}\mathrm{V} \\
\%\end{array}$ \\
\hline $0,00-0,20$ & 5,3 & 6,7 & 26,0 & 1,4 & 0,15 & 4,2 & 1,0 & 6,8 & 5,4 & 79,4 \\
\hline $0,20-0,40$ & 5,0 & 5,0 & 25,0 & 1,6 & 0,05 & 0,6 & 0,2 & 2,5 & 0,9 & 36,0 \\
\hline
\end{tabular}

Fonte: Elaboração dos autores.

As análises químicas de caracterização, teores de potássio e matéria orgânica foram realizadas em amostras de solos deformadas, conforme metodologias descrita em (SILVA, 2009). O delineamento experimental foi de blocos casualizados, com cinco repetições, em parcelas sub-subdivididas, sendo quatro doses de vinhaça ( 0 ; $450 ; 600$ e $\left.750 \mathrm{~m}^{3} \mathrm{ha}^{-1}\right)$, quatro camadas $(0,0-0,05$; $0,05-0,10 ; 0,10-0,20$ e $0,20-0,40 \mathrm{~m})$, e três épocas de coleta, aos 38, 75 e 111 dias após aplicação das doses de vinhaça, em parcelas de $24 \mathrm{~m}^{2}(6 \mathrm{~m} \mathrm{x} 4 \mathrm{~m})$.

A área vem sendo cultivada há três anos com cana-de-açúcar, utilizando a variedade RB 855453 de ciclo precoce, com espaçamento entre linhas de 1,5 m. O plantio da cultura ocorreu no ano de 2008, utilizando preparo convencional do solo, que consistiu de uma subsolagem a $50 \mathrm{~cm}$ de profundidade seguida de duas gradagens pesadas e uma gradagem niveladora. A adubação de plantio foi com $250 \mathrm{~kg} \mathrm{ha}^{-1}$ da fórmula 10-30-10 conforme recomendação técnica da usina. A colheita para determinação da produtividade foi realizada manualmente conforme metodologia descrita em (GHELLER et al., 1999).
As doses de vinhaça foram aplicadas em cada parcela no dia 10 de dezembro de 2010, quando as plantas apresentavam cinco a seis folhas totalmente expandidas. A análise química da vinhaça foi realizada diretamente pelo método de espectometria de plasma ICP (ICAP 6000 Thermo), através das diluições necessárias e resultou na composição: $\mathrm{P}$ $=67,4 \mathrm{mg} \mathrm{dm}^{-3} ; \mathrm{K}=388 \mathrm{mg} \mathrm{dm}^{-3} ; \mathrm{Mg}=84,0 \mathrm{mg}$ $\mathrm{dm}^{-3} ; \mathrm{Ca}=123 \mathrm{mg} \mathrm{dm}{ }^{-3} ; \mathrm{S}=95 \mathrm{mg} \mathrm{dm}^{-3} ; \mathrm{Zn}=1,5$ $\mathrm{mg} \mathrm{dm}{ }^{-3} ; \mathrm{Si}=8,2 \mathrm{mg} \mathrm{dm}^{-3} ; \mathrm{B}=0,04 \mathrm{mg} \mathrm{dm}^{-3} ; \mathrm{Fe}=$ $3,3 \mathrm{mg} \mathrm{dm}^{-3} ; \mathrm{Cu}=0,3 \mathrm{mg} \mathrm{dm}^{-3} ; \mathrm{Mn}=7,2 \mathrm{mg} \mathrm{dm}^{-3}$; $\mathrm{Al}=0,09 \mathrm{mg} \mathrm{dm}^{-3} ; \mathrm{Co}=0,01 \mathrm{mg} \mathrm{dm}^{-3} ; \mathrm{Cr}=0,03$ $\mathrm{mg} \mathrm{dm} \mathrm{d}^{-3} ; \mathrm{Ba}=0,01 \mathrm{mg} \mathrm{dm}^{-3} ; \mathrm{Cd}=0,0003 \mathrm{mg} \mathrm{dm}^{-3}$; $\mathrm{Ni}=0,03 \mathrm{mg} \mathrm{dm}^{-3} ; \mathrm{Sr}=0,8 \mathrm{mg} \mathrm{dm}^{-3}$ e V $=0,0008$ $\mathrm{mg} \mathrm{dm}^{-3}$. Para a determinação do $\mathrm{pH}$, condutividade elétrica e salinidade da vinhaça, foi utilizado um peagâmetro portátil, obtendo valores de 4,30;2,39 $\mathrm{mS} / \mathrm{cm}$ e 1,2 ppt respectivamente.

As coletas das amostras com estrutura preservada de solo foram realizadas aos 38, 75 e 111 dias após a aplicação dos tratamentos. Essas amostras de solo com estrutura preservada foram retiradas na forma de blocos $(25 \times 25 \times 25 \mathrm{~cm})$, que foram secos à sombra, destorroados manualmente de forma a 
separar os agregados segundo as superfícies de menor resistência e submetidos ao peneiramento via seca para a separação dos agregados, em tamanho entre 9,0 e 4,6 mm. Nesta classe de agregados, foram pesadas $5 \mathrm{~g}$ de agregados utilizados para a sonificação, em béquer com capacidade de 400 $\mathrm{mL}$, sendo adicionado $200 \mathrm{~mL}$ de água destilada, mantendo uma relação solo:água de 1:40. As sonificações foram realizadas utilizando um aparelho Misonix, modelo XL2020, operando no estágio nove do mostrador, com potência de $70 \mathrm{~W}$, durante 60 segundos (SÁ; LIMA; MELLO, 2002; RIBEIRO, 2009).

A ponta da haste do aparelho de ultrassom, com $175 \mathrm{~mm}$ de comprimento e diâmetro de $19 \mathrm{~mm}$, foi inserida na água a uma camada de $50 \mathrm{~mm}$. Após cada sonificação, as amostras foram passadas em peneira de malha $0,053 \mathrm{~mm}$, e o material retido foi quantificado como fração areia ou agregados do tamanho de areia, sendo que o restante contendo argila, silte e agregados com diâmetro inferior a $0,053 \mathrm{~mm}$ foram transferidos ao mesmo tempo para proveta com capacidade para $500 \mathrm{~mL}$. Esse volume foi completado com água destilada e a suspensão agitada durante 15 segundos para homogeneização. Com base na lei de Stokes, depois de adequados tempos de sedimentação da fração silte, subamostras de $10 \mathrm{~mL}$ foram coletadas para quantificação da fração argila. A fração silte foi obtida por diferença da soma da areia com a argila. Este procedimento possibilitou o cálculo do índice de dispersão, obtido pela relação: (fração $<0,053 \mathrm{~mm}$ ) / massa inicial de agregados secos, conforme descrito em Sá, Lima e Mello (2002).
A colheita da cana de açúcar foi realizada após um ciclo total de 10 meses. Foram coletados 10 colmos na área útil de cada parcela para determinação da produtividade em $\mathrm{Mg} \mathrm{ha}{ }^{-1}$, conforme descrito em (GHELLER et al., 1999).

Os dados foram submetidos à análise de variância através do teste $\mathrm{F}$, as médias do índice de dispersão de agregados, concentração de potássio e matéria orgânica em relação às doses de vinhaça, profundidade e época de coleta, foram analisadas pelo ajuste de regressão linear. As equações ajustadas do índice de dispersão de agregados do solo, doses de vinhaça e época de coleta foram avaliadas pelo teste F. Também foram obtidas as correlações de Pearson entre o índice de dispersão com a concentração de potássio e teor de matéria orgânica.

\section{Resultados e Discussão}

A análise de variância das médias da interação entre dose e profundidade, dose e tempo e profundidade e tempo, do índice de dispersão, concentração de potássio e matéria orgânica foram significativas a $1 \%$ de probabilidade, exceto para interação dose e tempo da variável matéria orgânica (Tabela 2).

Houve redução do índice de dispersão (ID) de agregados com aplicação das doses de vinhaça em todas as camadas estudadas, independente do período em que foram avaliados (Figura 1). Menor índice de dispersão de agregados indica menor predisposição dos agregados à dispersão, ou seja, possuem maior estabilidade (SÁ; LIMA; MELLO, 2002). 
Tabela 2. Valores de F e coeficiente de variação (CV) do índice de dispersão (ID), concentração de potássio (K) e matéria orgânica (M.O), após aplicação das doses de vinhaça.

\begin{tabular}{lccc}
\hline \multicolumn{1}{c}{ Fonte de variação } & ID & $\mathbf{K}$ & M.O \\
\hline Bloco & $0,67^{\text {ns }}$ & $6,60^{* *}$ & $0,26^{\text {ns }}$ \\
Dose & $59,35^{* *}$ & $178,85^{* *}$ & $22,24^{* *}$ \\
Profundidade & $108,25^{* *}$ & $54,38^{* *}$ & $51,38^{* *}$ \\
Tempo & $68,90^{* *}$ & $1765,85^{* *}$ & $10,43^{* *}$ \\
Dose x Profundidade & $3,63^{* *}$ & $6,29^{* *}$ & $4,37^{* *}$ \\
Dose x Tempo & $3,53^{* *}$ & $31,29^{* *}$ & $0,98^{\text {ns }}$ \\
Prof. x Tempo & $27,01^{* *}$ & $84,55^{* *}$ & $2,69^{* *}$ \\
Dose x Prof. x Tempo & $1,55^{\text {ns }}$ & $0,78^{\text {ns }}$ & $1,36^{\text {ns }}$ \\
CV 1 (\%) & 6,54 & 8,51 & 12,13 \\
CV 2 (\%) & 5,29 & 8,09 & 9,10 \\
CV 3 (\%) & 6,04 & 9,79 & 6,76 \\
\hline
\end{tabular}

(** significativo a $1 \%$ de probabilidade pelo teste $\mathrm{F}$. ns Não significativo a $5 \%$ de probabilidade pelo teste $\mathrm{F}$.)

Fonte: Elaboração dos autores.

Figura 1. Índice de dispersão (ID) em quatro camadas de um Latossolo Vermelho distroférrico de textura franco areno argilosa aos 38 (a), 75 (b) e 111 (c) dias após aplicação de quatro doses de vinhaça. *** Significativo a 5 e 1\% pelo teste F.

A
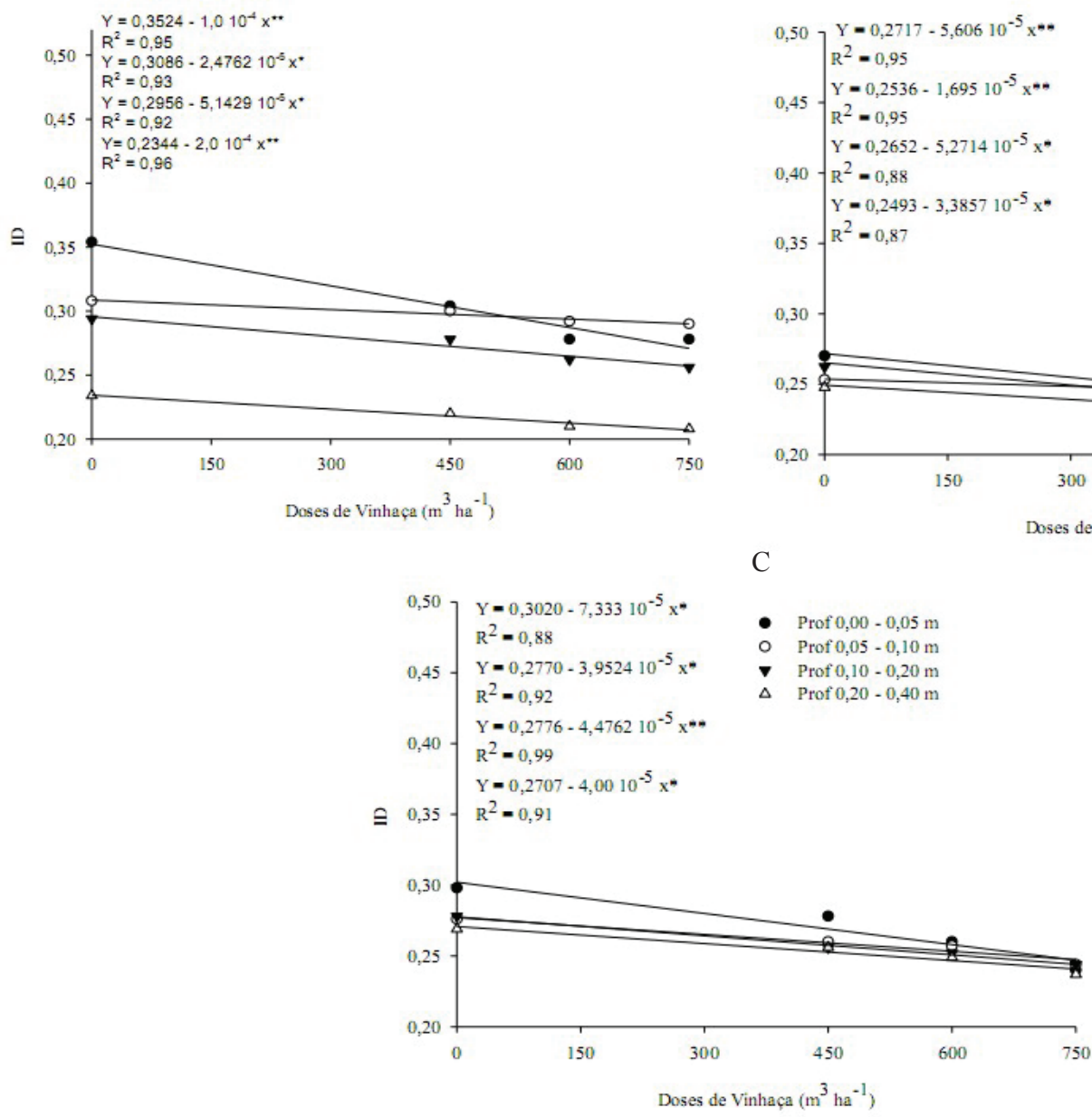

B

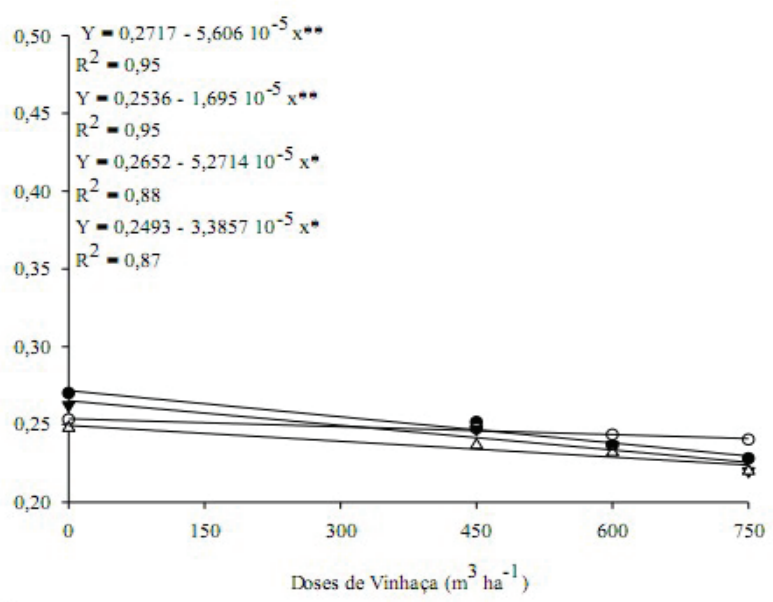

Fonte: Elaboração dos autores. 
Os valores de ID aos trinta e oito dias após aplicação da vinhaça decresceram. Para a camada de $0,00-0,05 \mathrm{~m}$, a queda foi de $21,5 \%$, passando de 0,354 para 0,278 . Com relação à camada de 0,05 - 0,10 m, a redução nos índices de dispersão foi menor, de apenas $6 \%$ da maior para menor dose. $\mathrm{Na}$ camada de 0,10 - 0,20 m o índice também decresceu com as doses de vinhaça, com uma queda de $13 \%$, passando de 0,294 para 0,256. A camada de 0,20 $0,40 \mathrm{~m}$ foi a que apresentou o menor ID tanto na menor quanto na maior dose, com valores de 0,23 e 0,20 respectivamente. Com queda de $11 \%$ do maior para o menor valor de ID. Fato este que pode ter ocorrido pela elevada concentração de potássio nesta camada e consequentemente floculação da argila, uma vez que o potássio é um dos cátions que mais facilmente é lixiviado para subsuperfície. Sá, Lima e Mello (2002) relataram que o tipo de uso do solo influencia a dispersão, tornando-a característica de cada tipo de solo e para cada sistema de manejo a que este solo é submetido.

Com relação ao índice de dispersão aos setenta e cinco dias após aplicação da vinhaça comportamento similar foi observado. Quando se aplicou a vinhaça observou-se um efeito acentuado na redução do ID na camada de 0,00 - 0,05 m quando comparado com as outras camadas. Já com relação à camada de 0,05 - 0,10 m a queda nos valores de ID foi de apenas $5,1 \%$. Observou-se também que nesta camada o valor máximo de ID na menor dose era de 0,253 e se encontrava abaixo quando comparado na mesma dose e com as camadas de 0,00 - 0,05 m e 0,10 $0,20 \mathrm{~m}$. Para a camada de 0,10 - 0,20 m ocorreu queda de $16,0 \%$ do maior para o menor valor de ID, que foram respectivamente de 0,262 e 0,220. A camada de 0,20 - 0,40 m apresentou os menores valores de índice de dispersão passando de 0,247 para 0,22 com queda real de $10,9 \%$.

Aos cento e onze dias após aplicação da vinhaça observou-se mesma tendência de diminuição nos valores de ID. Para camada de 0,00 - 0,05 m ocorreram às maiores reduções deste índice quando comparadas com as outras camadas estudadas, passando de 0,298 para 0,240 da menor para maior dose respectivamente, com queda de 19,5\%. Na camada de 0,05 - 0,10 $\mathrm{m}$ as quedas foram mais moderadas transpondo de 0,276 para 0,244 com redução de apenas $11,6 \%$. Nota-se que o valor máximo de ID na menor dose nesta camada, é o menor quando comparado com as camadas de 0,0 0,05 e $0,10-0,20 \mathrm{~m}$. Na camada de $0,10-0,20 \mathrm{~m}$ a redução deste índice foi de $12,2 \%$ passando de 0,278 para 0,244. Já a camada de 0,20 - 0,40 m apresentou o menor valor de ID da menor para maior dose, com valores de 0,27 para 0,24 , representando queda real de 11,1\%. Quanto menor o índice de dispersão maior é a estabilidade dos agregados do solo, o que segundo Santos (2008) é um indicativo de aumento da qualidade física do solo.

O índice de dispersão, de forma análoga à estabilidade de agregados do solo está relacionado com fenômenos físicos, químicos e mineralógicos do solo. Com base nestas relações vale salientar que como os teores de matéria orgânica diminuíram com a camada dos solos, espera-se que nas camadas subsuperficiais a estabilidade dos agregados esteja mais relacionada com a mineralogia do solo, o que está de acordo com van Lier (2010), que afirma que em virtude do baixo teor de matéria orgânica no horizonte B dos Latossolos em geral sua participação é bem discreta na estruturação destes solos. Com relação a este estudo e considerando que a estrutura é um atributo dinâmico do solo, sendo fortemente afetada por atividades biológicas e notadamente por práticas de manejo do solo, a aplicação de doses de vinhaça forneceu uma quantidade significativa de matéria orgânica para a subsuperfície dos solos, dentro dos limites de camada que foram considerados nesse estudo.

Ainda com relação à matéria orgânica, o incremento promovido pela maior dose de vinhaça, foi eficaz no aumento da estabilidade dos agregados, o que está de acordo com Balesdent, Chenu e Balabane (2000) que afirmaram que os sistemas de manejo com aplicação e conservação de resíduos orgânicos aumentam os estoques de 
matéria orgânica e a estabilidade de agregados. Conforme as equações de regressão a concentração de potássio no solo aumentou da menor para maior dose de vinhaça (Figura 2). O índice de dispersão de agregados correlacionou-se de modo significativo $(\mathrm{p}<0,01)$ e negativo com a concentração de potássio nas três épocas de coleta após aplicação da vinhaça em todas as camadas.

Figura 2. Teor de potássio em quatro camadas de um Latossolo Vermelho distroférrico de textura franco areno argilosa aos 38 (a), 75 (b) e 111 (c) dias após aplicação de quatro doses de vinhaça. *** Significativo a 5 e 1\% pelo teste F.

A

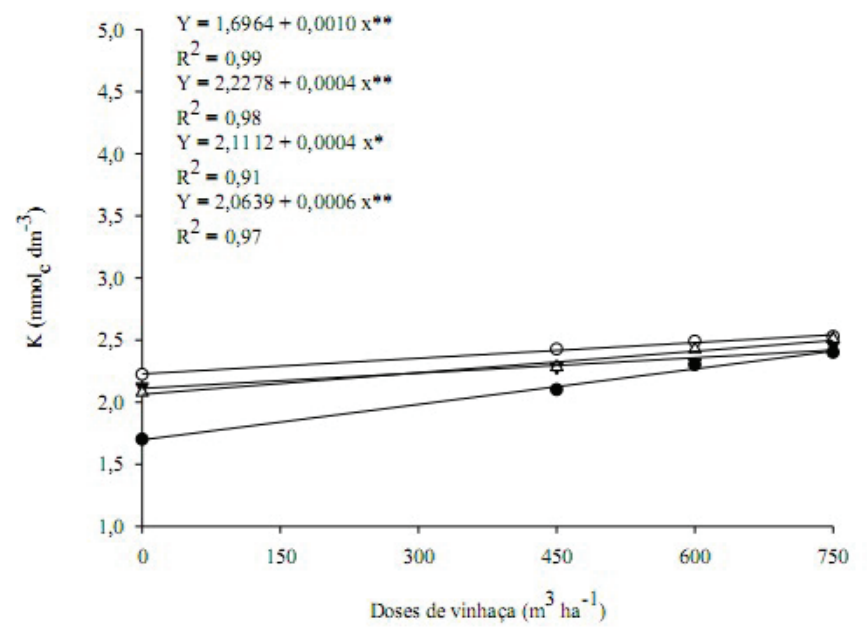

B

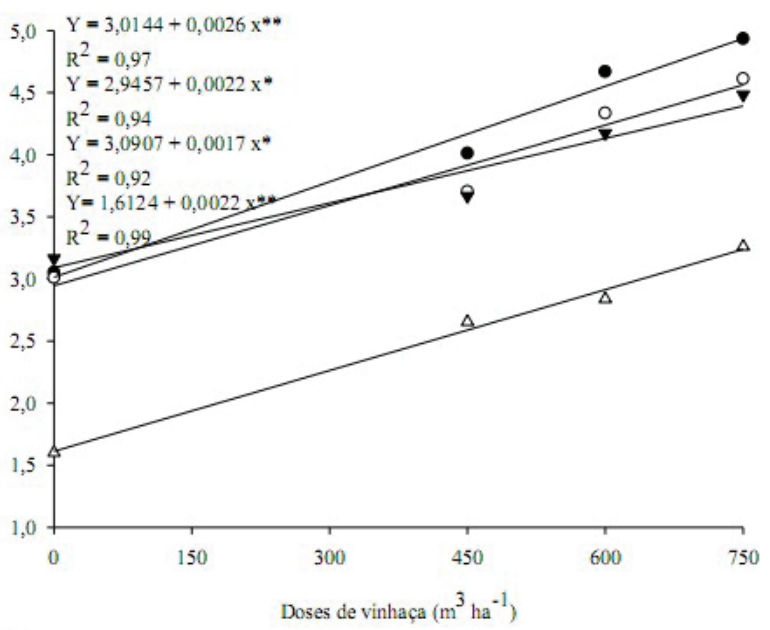

$\mathrm{C}$

- Prof $0,00-0,05 \mathrm{~m}$ Prof $0,05-0,10 \mathrm{~m}$ > Prof $0,10-0,20 \mathrm{~m}$ $\Delta \quad$ Prof $0,20-0,40 \mathrm{~m}$

Fonte: Elaboração dos autores.

Assim o fornecimento de nutrientes ao solo através da adição de resíduos como a vinhaça melhora sua fertilidade, bem como dependendo de sua dose e concentração catiônica atua beneficamente na melhoria dos atributos físicos do solo, através do aumento da energia de ligação do íon com a superfície da partícula, favorecendo à formação de agregados maiores e mais estáveis em água, o que está de acordo com Meurer (2010) que descreve que ao ocorrer o aumento da concentração de cátions de qualquer valência também se aumenta a estabilidade dos agregados e consequentemente diminui-se o índice de dispersão, o que ocorre pela diminuição da dupla 
camada difusa causada pelo aumento das forças de ligação entre as partículas.

Com relação à matéria orgânica observou-se aumento do teor no solo da menor para maior dose de vinhaça (Figura 3). O índice de dispersão de agregados correlacionou-se de modo significativo $(p<0,01)$ e negativo com a concentração de matéria orgânica nas três épocas de coleta após aplicação da vinhaça em todas as camadas.

Figura 3. Teor de matéria orgânica em quatro camadas de um Latossolo Vermelho distroférrico de textura franco areno argilosa aos 38 (a), 75 (b) e 111 (c) dias após aplicação de quatro doses de vinhaça. **** Significativo a 5 e $1 \%$ pelo teste $\mathrm{F}$.
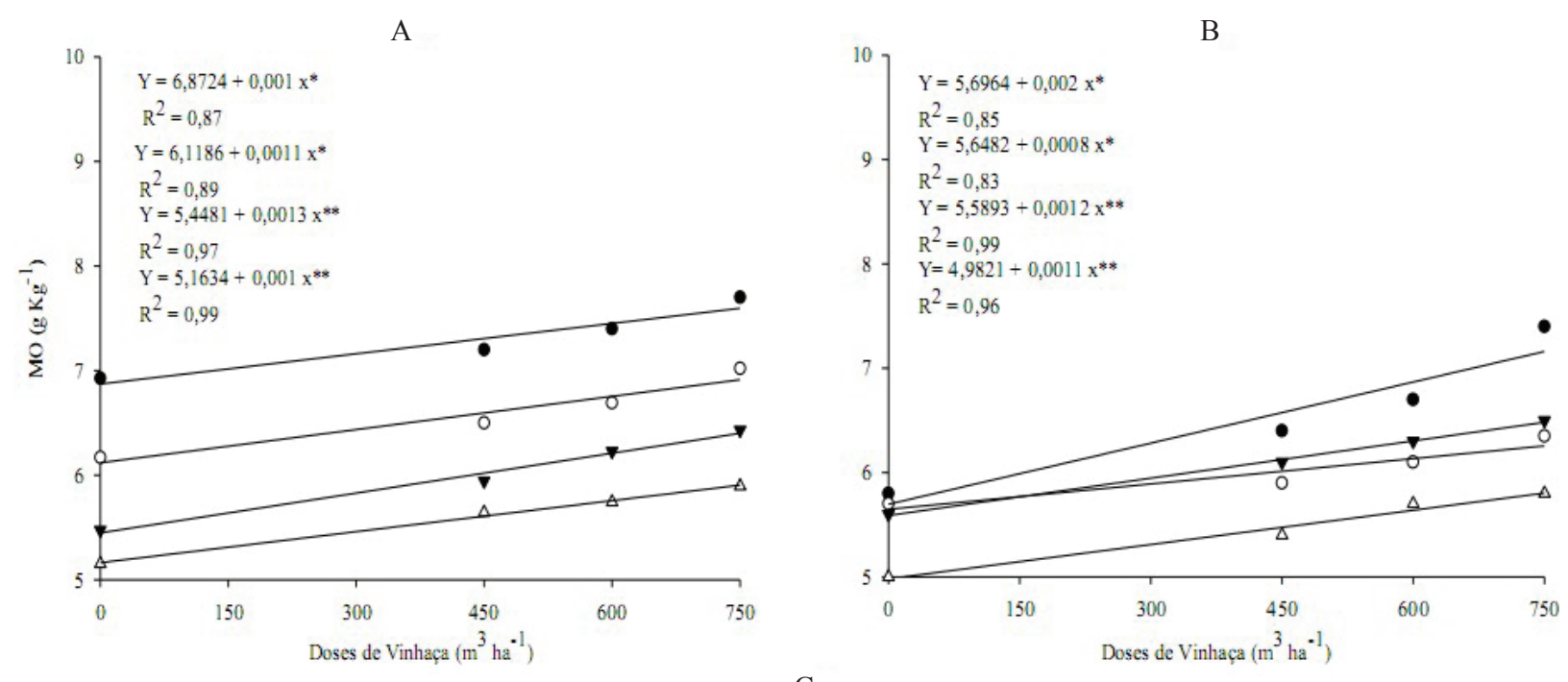

C

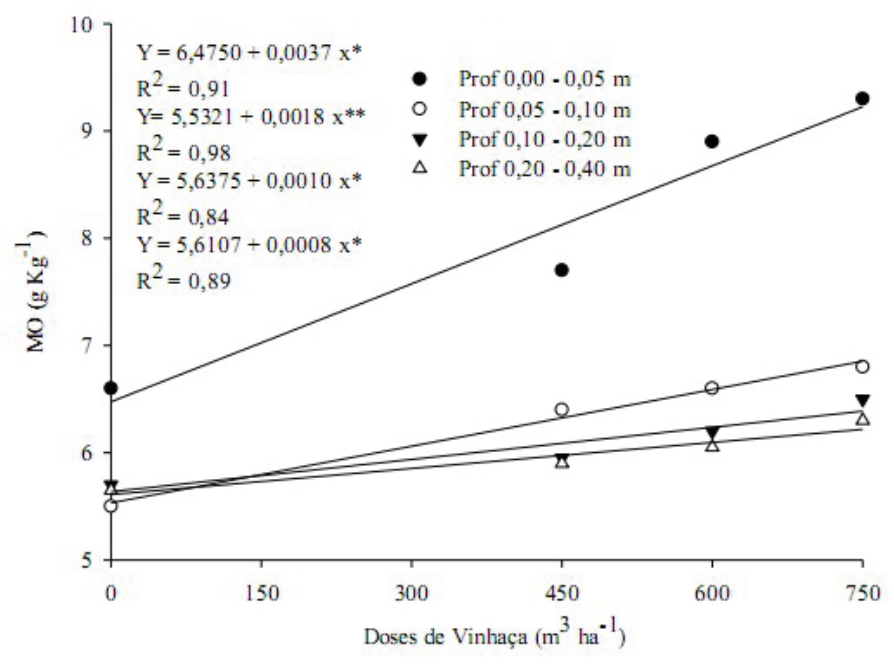

Fonte: Elaboração dos autores.

O aumento da concentração da matéria orgânica promovida pela adição das doses de vinhaça é benéfico tanto para a melhoria da fertilidade do solo através do aumento da capacidade de troca catiônica, bem como por possuir ação cimentante nos agregados, atuando na proteção dos mesmos. Esta proteção conferida pela matéria orgânica é responsável pelo aumento da estabilidade dos agregados em água. 
Com a maturação fisiológica da cultura procedeu-se à avaliação da produtividade, que se correlacionou de modo significativo $(\mathrm{P}<0,01)$ e positivo com os teores de potássio e matéria orgânica, constatando-se aumento da produtividade (Figura 4).

Figura 4. Correlação entre produtividade da cana-de-açúcar e teor de potássio e matéria orgânica de um Latossolo Vermelho distroférrico. ** Significativo a $1 \%$ pelo teste $\mathrm{F}$.

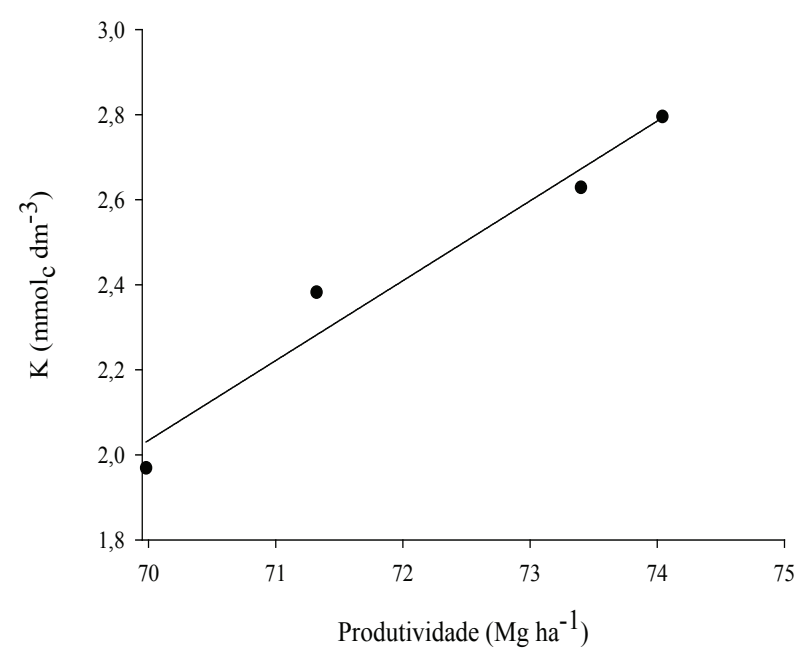

Fonte: Elaboração dos autores.

Os resultados da produtividade exprimem indiretamente os benefícios decorrentes das doses da vinhaça na qualidade física do solo, que ao fornecer potássio e matéria orgânica proporcionam uma melhor estruturação do solo, o que pode beneficiar o desenvolvimento radicular das plantas de canade-açúcar ao explorar um maior volume de solo, e consequentemente ter efeito no crescimento da parte área e no acúmulo de fotoassimilados pela planta, o que está de acordo com (MALAVOLTA, 2006). Esses autores ainda citam que o fornecimento de potássio favorece a síntese e acúmulo de sacarose.

Para Santos et al. (2008) esse incremento nos teores de matéria orgânica beneficiam a agregação do solo, melhorando os atributos físicos como a densidade do solo, porosidade, aeração, capacidade de retenção e infiltração de água, entre outros, que são fundamentais para à capacidade produtiva.

Camilotti (2006), ao avaliar treze experimentos em cana soca, verificou que a vinhaça proporcionou aumento de produção da cana soca, o que corrobora

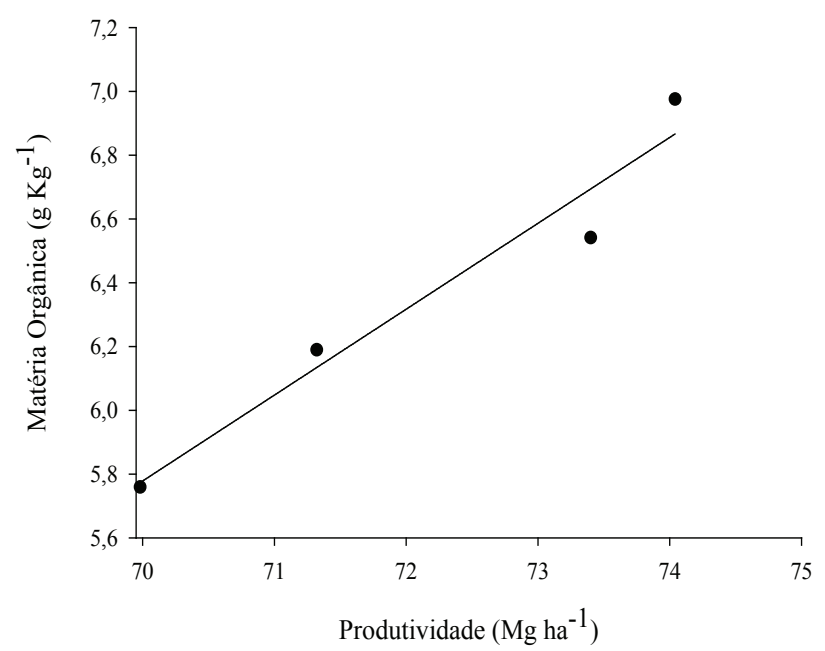

Barbosa et al. (2006), Tasso Júnior et al. (2007) que encontraram maiores produtividades na cana soca com aplicação de até $270 \mathrm{~m}^{3} \mathrm{ha}^{-1}$ de vinhaça combinado com adubos minerais em um Latossolo Vermelho-Amarelo.

\section{Conclusões}

A aplicação de 450, 600 e $750 \mathrm{~m}^{3} \mathrm{ha}^{-1}$ de vinhaça reduz o índice de dispersão dos agregados em Latossolo Vermelho distroférrico cultivado com cana-de-açúcar.

Os teores de potássio e de matéria orgânica no solo aumentam com as doses de vinhaça e se correlacionam positivamente com a produtividade da cana-de-açúcar.

\section{Agradecimentos}

Ao Conselho Nacional de Desenvolvimento Científico e Tecnológico pela bolsa de mestrado 
concedida ao primeiro autor. E a Usina Monte Verde, BUNGE-SA pela concessão da área experimental.

\section{Referências}

BALESDENT, J.; CHENU, C.; BALABANE, M. Relationship of soil organic matter dynamics to physical protection and tillage. Soil and tillage research, Amesterdam, v. 53, n. 3, p. 215-230, 2000.

BARBOSA, V.; DURINGA, A. M. P. R.; GLÓRIA, N. A.; MUTTON, M. A. Uso de vinhaça concentrada na adubação de soqueira da cana-de-açúcar. STAB, Piracicaba, v. 24, n. 6, p. 26-31, 2006.

CAMILOTTI, F. Efeitos no solo e em plantas de cana-deaçúcar cultivadas com lodo de esgoto e vinhaça. 2006. Tese (Doutorado em Solos) - Universidade Estadual Paulista, Jaboticabal.

CAMILOTTI, F.; ANDRIOLI, I.; MARQUES, M. O.; SILVA, A. R. S.; JÚNIOR, L. C. T.; NOBILE, F. O. Atributos físicos de um latossolo cultivado com cana-de-açúcar após aplicações de lodo de esgoto e vinhaça. Engenharia Agrícola, Jaboticabal, v. 26, n. 3, p. 738-747, 2006.

CANELLAS, L. P.; VELLOSO, A. C. X.; MARCIANO, C. R.; RAMALHO, J. F. G. P.; RUMJANEK, V. M.; REZENDE, C. E.; SANTOS, G. A. Propriedades químicas de um Cambissolo cultivado com cana-deaçúcar, com preservação do palhiço e adição de vinhaça por longo tempo. Revista Brasileira de Ciência do Solo, Viçosa, MG, v. 27, n. 5, p. 935-44, 2003.

CENTURION, J. F.; FREDDI, O. S.; ARATANI, R. G.; METZENER, A. F. M.; BEUTLER, A. N.; ANDRIOLI, I. Influência do cultivo da cana-de-açúcar e da mineralogia da fração argila nas propriedades físicas de Latossolos vermelhos. Revista Brasileira de Ciência do Solo, Viçosa, MG, v. 31, n. 5, p. 199-209, 2007.

DEXTER, A. R.; YOUNGS, I. M. Soil physics toward 2000. Soil Tillage Research, Amsterdam, v. 24, n. 10, p. 101-106, 1992.

GHELLER, A. C. A.; MATSUOKA, S.; MASUDA, Y.; HOFFMANN, H. P.; ARIZONO, H.; GARCIA, A. A. F. Manual de método alternativo para medição da produção da cana-de-açúcar. Araras, UFSCar-CCADBV, 1999. p. 7.

LAVANHOLI, M. G. D. Qualidade da cana-de-açúcar como matéria-prima para produção de açúcar e álcool. In: DINARDO-MIRANDA, L. L.; VASCONCELOS, A. C. M.; LANDELL, M. G. A. (Ed.). Cana-de-açúcar. Campinas: Instituto Agronômico, 2010. 882 p.

MALAVOLTA, E. Manual de nutrição mineral de plantas. 2. ed. São Paulo: Ceres, 2006. 638 p.
MEURER, E. J. Fundamentos de química do solo. 4. ed. Porto Alegre: Evangraf Ltda, 2010. 266 p.

PASSARIN, A. L.; RODRIGUEIRO, E. L.; ROBAINA, C. R. P.; MEDINA, C. C. Caracterização de agregados em um Latossolo vermelho distroférrico típico submetido a diferentes doses de vinhaça. Revista Brasileira de Ciência do Solo, Viçosa, MG, v. 31, n. 6, p. 1255-1260, 2007.

RIBEIRO, B. T. Aplicação de vinhaça em solos: efeito no balanço de cargas e dispersão de partículas. 2009. Tese (Doutorado em Agronomia) - Universidade Federal de Lavras, Lavras.

SÁ, M. A. C.; LIMA, J. M.; MELLO, C. R. Nível de energia ultra-sônica para estudo da estabilidade de agregados de um Latossolo sob diferentes usos. Pesquisa Agropecuária Brasileira, Brasília, v. 37, n. 11, p. 16491655, 2002.

SANTOS, G. A. Fundamentos da matéria orgânica do solo: ecossistemas tropicais \& subtropicais. Porto Alegre: Metrópole, 2008. 654 p.

SILVA, A. J. N.; CABEDA, S. V.; CARVALHO, F. G.; LIMA, J. F. W. F. Alterações físicas de um Argissolo Amarelo sob diferentes sistemas de uso e manejo. Revista Brasileira de Engenharia Agrícola e Ambiental, Campina Grande, v. 10, n. 1, p. 76-83, 2006.

SILVA, C. S. Manual da análises químicas de solos, plantas e fertilizantes. Brasília: Embrapa Informação e Tecnologia, 2009. $627 \mathrm{p}$.

TASSO JÚNIOR, L. C. T.; MARQUES, M. O.; FRANCO, A.; NOGUEIRA, G. A.; NOBILE, F.; CAMILOTTI, F.; SILVA, A. R. Produtividade e qualidade de cana-deaçúcar cultivada em solo tratado com lodo de esgoto, vinhaça e adubos minerais. Engenharia Agrícola, Jaboticabal, v. 27, n. 1, p. 276-283, 2007.

van LIER, Q. J. Física do solo. Viçosa: SBCS, 2010. 298 p.

VICENTE, T. F. S.; PEDROSA, E. M. R.; ROLIM, M. M.; OLIVEIRA, V. S.; OLIVEIRA, A. K. S.; SOUZA, A. M. P. T. Relações de atributos do solo e estabilidade de agregados em canaviais com e sem vinhaça. Revista Brasileira de Engenharia Agrícola e Ambiental, Campina Grande, v. 16, n. 11, p. 1215-1222, 2012.

VITORINO, A. C. T.; FERREIRA, M. M.; CURI, N.; LIMA, J. M.; SILVA, M. L. N.; MOTTA, P. E. F. Mineralogia, química e estabilidade de agregados do tamanho silte de solos da Região Sudeste do Brasil. Pesquisa Agropecuaria Brasileira, Brasília, v. 38, n. 1, p. 133-141, 2003. 